\title{
Surface Strengthening of High-Alloyed Martensitic Steel by Staged Nitriding
}

\author{
Petr Bibikov ${ }^{1}$, Larisa Petrova ${ }^{2,}$, Irina Belashova ${ }^{2}$, and Peter Demin ${ }^{2}$ \\ ${ }^{1}$ Moscow Aviation Institute (National Research University), 125993 Volokolamskoe shosse, 4, \\ Moscow, Russia \\ ${ }^{2}$ MADI University, Technology of structural materials department, 125319 Leningradskiy prospect 64 \\ Moscow, Russia
}

\begin{abstract}
Gas nitriding processes with cyclical rotation of ammonia and ammonia/air atmospheres are suggested for surface strengthening of martensitic Cr-Ni-W-Mo-V steel. One-, two-, and three-staged processes were studied differing by gas atmospheres at the final stage of processes. Microstructure and phase composition of received diffusion layers were examined. Results of microhardness, wear and impact toughness tests are discussed in correspondence with the layers structure.
\end{abstract}

\section{Introduction}

Martensitic steel $13 \mathrm{Cr} 11 \mathrm{Ni} 2 \mathrm{~W} 2 \mathrm{MoV}$ is applying as corrosion resistant and heat resistant steel for loaded components of aviation production. For increase of its wear resistance, nitriding is used at temperature $600^{\circ} \mathrm{C}$ which increase hardness of nitrided layer up to $850 \mathrm{HV}$.

It is known that nitriding of high-alloyed steels have long duration [1], thus search of techniques for diffusion layer growth acceleration is topical. Plasma nitriding is considered one of the most effective ways for the process intensification. Different variations of the process are widely used for surface strengthening of austenitic and martensitic steels [2-4].

Another way for nitriding acceleration consists in application of staged or cyclic processes with changing of nitriding potential. It was shown that cyclic processes in changing ammonia-air atmospheres provide specific opportunities for phase composition regulation and for achievement of given properties of nitrided surface $[5,6]$.

The purpose of the study consists in examination of structure and properties of highalloyed martensitic steel after staged gas nitriding with cyclical rotation of ammonia and ammonia/air atmospheres.

\section{Methods of study}

Samples of $13 \mathrm{Cr} 11 \mathrm{Ni} 2 \mathrm{~W} 2 \mathrm{MoV}$ were used after standard heat treatment: quenching from $1000^{\circ} \mathrm{C}$, and aging at $620-680^{\circ} \mathrm{C}$, for providing necessary properties of a core. Table 1 shows chemical composition of the steel.

\footnotetext{
*Corresponding author: petrova_madi@mail.ru
} 
Laboratory experiments on staged nitriding were carried out in a shaft furnace. Processes regimes are shown in the Table 2. At the first and at the second stages the saturation was carried out in atmospheres of rotating ammonia and ammonia-air $(30 \% / 70 \%)$. The third stage in pure ammonia was applied for decrease of nitrogen activity and for resorption of previously formed compound zone. The temperature of the $1^{\text {st }}$ stage was $530^{\circ} \mathrm{C}$, and the temperature of the $2^{\text {nd }}$ and the $3^{\text {rd }}$ stages was $580^{\circ} \mathrm{C}$. The total processes duration was 12 hours.

Table 1. Chemical composition of steel $13 \mathrm{Cr} 11 \mathrm{Ni} 2 \mathrm{~W} 2 \mathrm{MoV}$, weight $\%$ of elements

\begin{tabular}{|l|l|c|c|c|c|c|c|c|c|l|}
\hline $\mathrm{C}$ & $\mathrm{Cr}$ & $\mathrm{Ni}$ & $\mathrm{V}$ & $\mathrm{W}$ & $\mathrm{Mo}$ & $\mathrm{Si}$ & $\mathrm{Mn}$ & $\mathrm{S}$ & $\mathrm{P}$ & $\mathrm{Fe}$ \\
\hline $\begin{array}{c}0.10- \\
0.16\end{array}$ & $10.5-$ & $1.5-$ & $0.18-$ & $1.6-$ & $0.35-$ & $\leq 0.6$ & $\leq 0.6$ & $\leq 0.02$ & $\leq 0.03$ & Bal. \\
12.0 & 0.30 & 2.0 & 0.50 & & & & & \\
\hline
\end{tabular}

Table 2. Staged nitriding regimes

\begin{tabular}{|l|l|l|l|}
\hline Process No. & Stage 1 & Stage 2 & Stage 3 \\
\hline I & $\mathrm{NH}_{3} / \mathrm{NH}_{3}+$ air, 12 h & - & - \\
\hline II & $\mathrm{NH}_{3} / \mathrm{NH}_{3}+$ air, 3 h & $\mathrm{NH}_{3} / \mathrm{NH}_{3}+$ air, 9 h & - \\
\hline III & $\mathrm{NH}_{3} / \mathrm{NH}_{3}+$ air, 3 h & $\mathrm{NH}_{3} / \mathrm{NH}_{3}+$ air, 6 h & $\mathrm{NH}_{3}, 3 \mathrm{~h}$ \\
\hline
\end{tabular}

Metallographic examinations of samples' cross-sections were carried out in MMP-2P microscope with magnifications of x100 and x500. Microhardnesss of nitrided layers was determined by PMT-3 measurer. X-ray diffraction method was applied for identification of phases in nitrided layers on DRON-3 diffractometer in Cr-radiation.

Wear resistance was measured by depth wear parameter in dry friction conditions. Wear tests were carried out on TE-200/2 JEAN WIRTH machine at room temperature. Samples of $12 \mathrm{~mm}$ diameter and $5 \mathrm{~mm}$ thickness moved at linear speed $10.74 \mathrm{~km} / \mathrm{h}$. Disk of 45 grade steel with the hardness 28 HRC was used as a counter body. Samples' thickness changes were measured through fixed distances of the friction path.

Dynamic tests for impact toughness examination were conducted according to the national Standard (GOST 9454-78) on samples with U-shaped stress concentrators with usage of pendulum hammer TCKM 300 under the load of $150 \mathrm{~J}$. The measurements were averaged over the results of 3 tests for each kind of treatment.

\section{Results and discussion}

Micrographs of nitrided layers received after staged processes show their visually observed boundary with the steel core (Fig. 1). This gives the possibility to evaluate layers thickness: the average values are $80 \mu \mathrm{m}$ after the process I, and $110 \ldots 120 \mu \mathrm{m}$ after the processes II and III. Increase of layers thickness after staged processes is explained mainly by the temperature rise at the $2^{\text {nd }}$ and the $3^{\text {rd }}$ stages.

Nitrided layers have specific martensitic structure; high etching of the layers is the consequence of oversaturated nitrogen concentration in solid solution.

We can observe a thin surface compound zone after one- and two-staged processes; primary precipitation of $\varepsilon$-phase at the surface was detected by X-ray diffraction analysis (Table 3). After three-staged process with the final stage in pure ammonia, dissolution of $\varepsilon$ phase occurs (Fig. $1 \mathrm{c}$ ) due to the high ammonia dissociation degree (up to 80\%). X-ray diffraction analysis shows increase of $\gamma^{\prime}-\mathrm{Fe}_{4} \mathrm{~N}$ mole fraction, and $\alpha^{\prime}$-martensite appearance directly at the surface together with retained austenite (Table 3). 


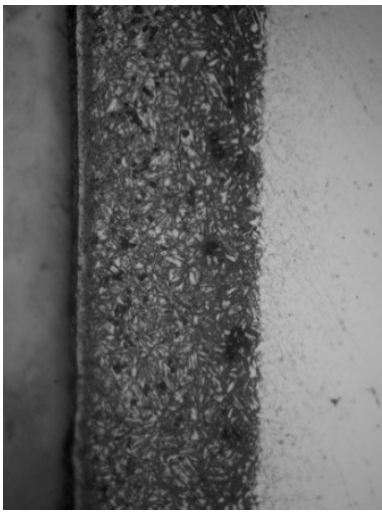

a)

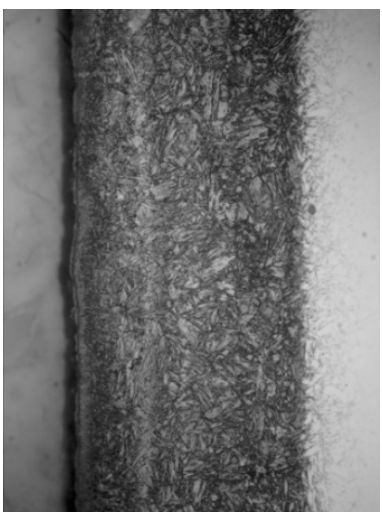

b)

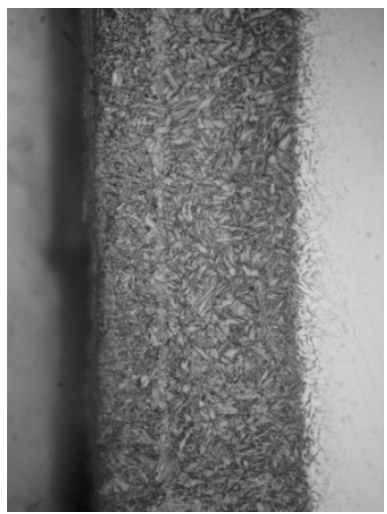

c)

Fig. 1. Micrographs of nitrided samples after processes I (a), II (b) and III (c)

Table 3. Phase composition of nitrided surface

\begin{tabular}{|l|l|l|l|l|}
\hline \multirow{2}{*}{ Process No. } & \multicolumn{4}{|c|}{ Phases and their relative mole fraction, \% } \\
\cline { 2 - 5 } & $\varepsilon-\mathrm{Fe}_{2-3} \mathrm{~N}$ & $\gamma^{\prime}-\mathrm{Fe}_{4} \mathrm{~N}$ & $\gamma-\mathrm{Fe}$ & $\alpha^{\prime}$-martensite \\
\hline I & 72.05 & 27.95 & - & - \\
\hline II & 87.60 & 8.97 & 3.43 & - \\
\hline III & - & 72.39 & 15.53 & 12.09 \\
\hline
\end{tabular}

As we can see at microhardness profiles (Fig. 2), maximum strengthening of the layer was achieved after one-staged nitriding at $530^{\circ} \mathrm{C} 12$ hours (process I). But such process gives sharp microhardness gradient at the boundary with the core. Increase of nitriding temperature at the $2^{\text {nd }}$ and at the $3^{\text {rd }}$ stages (processes II and III) reduces hardness but provides growth of layers.

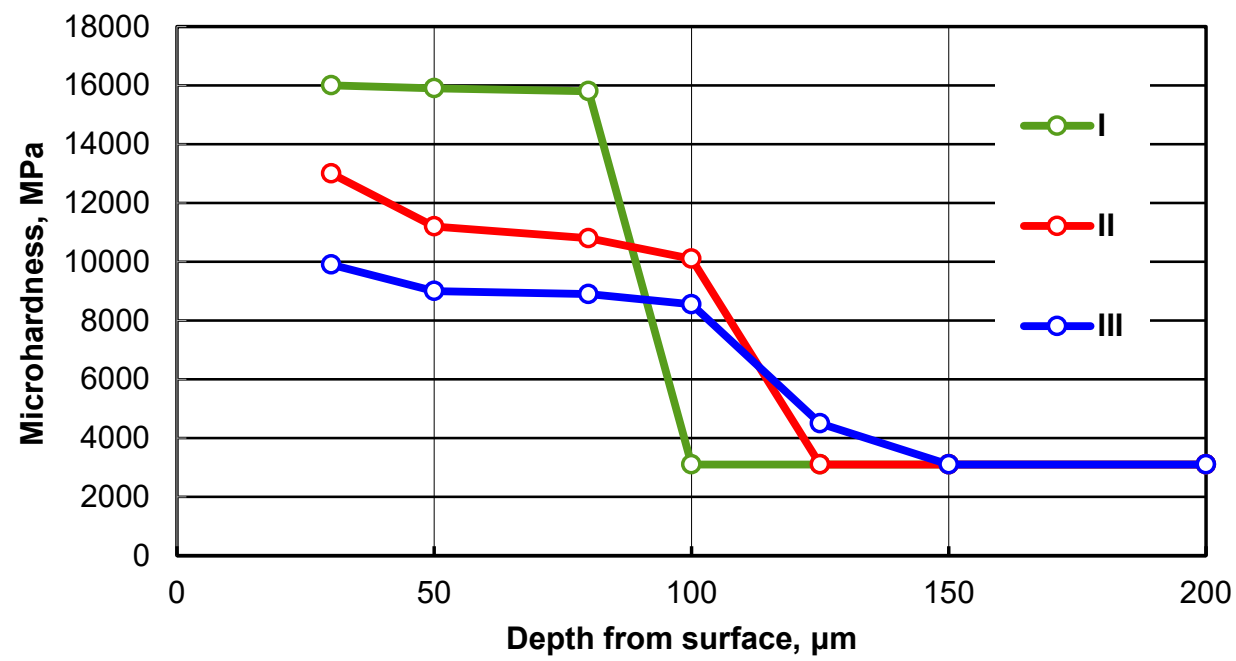

Fig. 2. Microhardness profiles of nitrided layers after processes I, II and III 
Three-staged process makes microhardness profile smoother due to nitrogen redistribution at the resorption stage. This is an important factor of strains decrease at the layer-core boundary. Evaluation of the layer thickness at the microhardness profile gives the value up to $140 \mu \mathrm{m}$. This means that increased nitrogen concentration takes place under the visually observed nitrided layer.

Wear tests have shown high wear resistance of steel samples after all studied processes. Wear depth parameters are almost the same with some better hand of staged processes despite the lower hardness of the layers (Fig. 3).

Dynamic impact tests found decrease of impact toughness after nitriding comparing to the samples after standard heat treatment (Fig. 4). Three-staged nitriding shows less negative effect on toughness due to the absence of $\varepsilon$-phase zone. Brittle fractures are observed by fractographic examinations due to the presence of martensite (Fig. 5). However, the samples after the 3 -staged process as well as non-nitrided specimens have small traces of plastic deformation (Fig. 5 a, c).

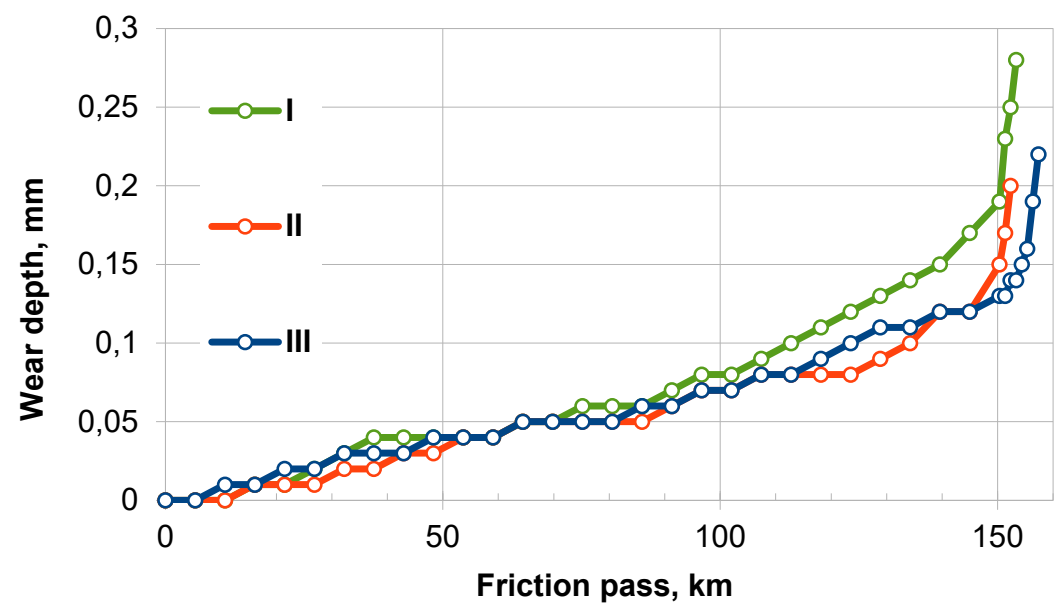

Fig. 3. Wear depth parameters of nitrided steel after processes I, II and III

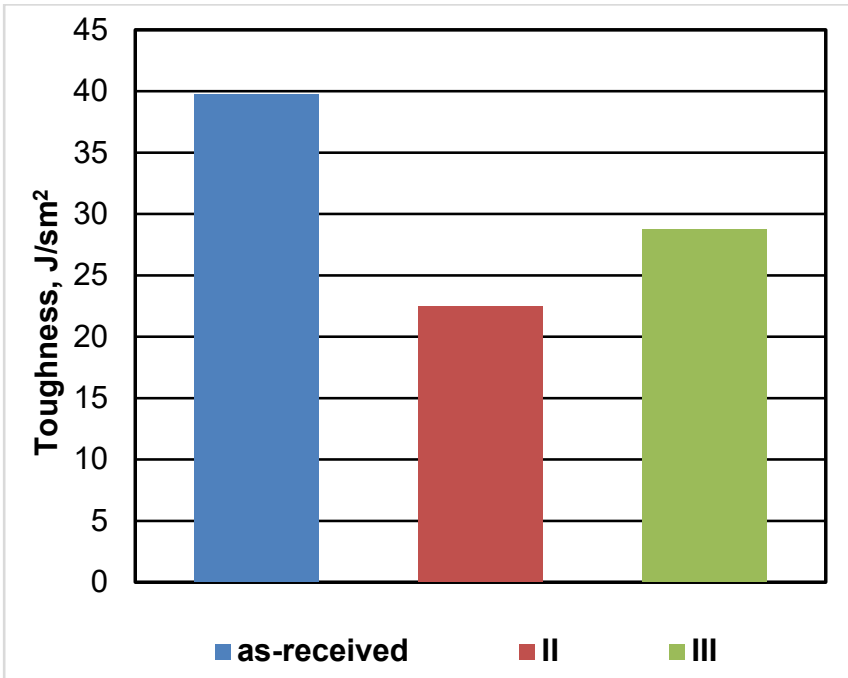

Fig.4. Impact toughness of steel without nitriding, and after processes II and III 


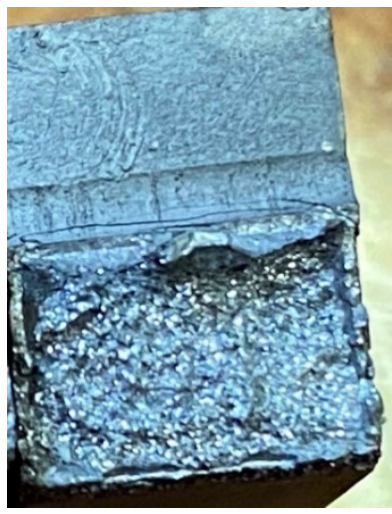

a)

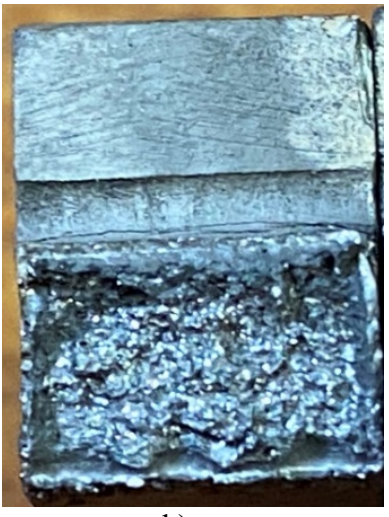

b)

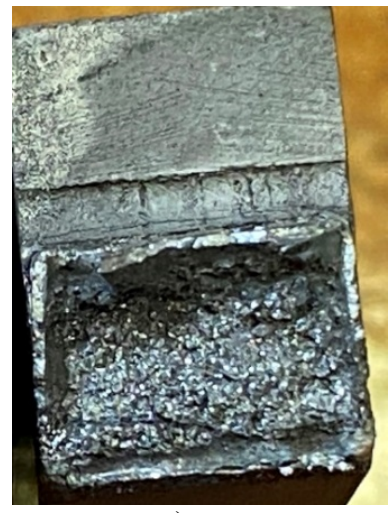

c)

Fig. 5. Fractographic images of steel samples without nitriding (a), after processes II (b) and III (c)

\section{Conclusions}

Metallographic examinations and X-ray phase analysis of martensitic steel $13 \mathrm{Cr} 11 \mathrm{Ni} 2 \mathrm{~W} 2 \mathrm{MoV}$ after nitriding with different number of stages of varying temperatures and saturating atmospheres shows the advantages of three-staged process with final stage in ammonia. Acceleration of the layer growth is achieved, and strengthened layer with optimal structure and properties is formed. Flow microhardness profile with gradual decline to the core provides the reduction of internal residual stresses. After three-staged nitriding, the steel has high wear resistance and keeps satisfactory toughness due to the absence of $\varepsilon$ phase.

The material was prepared within the framework of scientific research under the project №FSFM2020-0011 (2019-1342); experimental studies were carried out using the equipment of the MADI Centre of collective usage.

\section{References}

1. Z.L. Zhang, T. Bell, Surf. Eng., 1 (1985)

2. K.R.M. Rao, C. Nouveau, K. Trinadh, Trans. Indian Inst. Met., 73 (2020)

3. C.E. Pinedo, W.A. Monteiro, Surface and Coatings Technology, 179, 2-3 (2004)

4. U.G. Khusainov, K.N. Ramazanov, R.S. Esipov, Diffusion and Defect Data. Pt A Defect and Diffusion Forum, 383 (2018)

5. I.S. Belashova, L.G. Petrova, V.D.Aleksandrov, P.E.Demin, Russian Engineering Research, 38, 1 (2018)

6. I.S. Belashova, P.S. Bibikov, L.G. Petrova, A.S. Sergeeva, 2021 IOP Conf. Ser.: Mater. Sci. Eng., 1064 (2021) 